\title{
Towards a Real Time Energy Management Strategy for Hybrid Wind-PV Power System based on Hierarchical Distribution of Loads
}

\author{
Abdelhadi Raihani ${ }^{1}$, Tajeddine Khalili ${ }^{2}$, Mohamed Rafik ${ }^{3}$, Mohammed Hicham Zaggaf ${ }^{4}$, Omar Bouattane ${ }^{5}$ \\ SSDIA Lab, ENSET Mohammedia Hassan II University of Casablanca, Morocco
}

\begin{abstract}
Energy management is a crucial aspect for achieving energy efficiency within a Hybrid Renewable energy power station. Load being unbalanced through the day, a reasonable power management can avoid energy dissipation and unnecessary grid solicitation. This article presents an energy management strategy in a real case scenario of a hybrid windsolar power station in the ENSET campus. The approach manages energy provided by wind turbines and multiple photovoltaic panels, using a power bank as backup source. in this study actual data involving wind speed, solar radiation, load profile and energy generation was collected. Different scenarios were simulated in order to synthesize an efficient energy management and load balancing system with possible load forecasting capability. In all the simulated scenarios the study emphasizes a minimal solicitation of the grid.
\end{abstract}

Keywords-Energy management; hybrid renewable energy sources; grid injection; loads distribution; energy forecasting; load forecasting

\section{INTRODUCTION}

Renewable energy sources (RES) management today is a critical field of research. This growing interest is mainly due to the depletion of conventional energy resources (coal, oil, natural gas) and mass emission of greenhouse gas [1]. In addition, prices of non-renewable energy increased considerably during recent years due to the high demand. Thus, using renewable energy sources, such as wind and sun is a very adapted solution for today's energy crisis. Hybrid Wind-Solar power generation systems have their fair share of interest among energy supplying systems. The abundance of these natural resources will help the fast growing industrial world to decrease the energy consumption cost in the near future. Despite the high abundances of wind and solar energy, their availability is unpredictable in a given location. Therefore, hybrid renewable energy systems (HRES) are frequently investigated in order to face the intermittence of renewable energy resources.

Two or more forms of energy sources can be combined in a HRES in order to face the limitations encountered in single source based systems. Thus, to ensure the reliability and continuity of the HRES, stable and predictable power sources, such as power-banks, electro-generators or the grid are used. Thereby, in stand-alone applications, Power Banks can store the excess of energy and exploit it when load demand is higher than the available power [2, 3, 4]. This type of architectures can even help to inject excess of energy into the grid when there is no need to store or exploit power immediately. During this delicate operation, inverters and other power converters in the HRES control the quality of the supplied power by adapting instantly the voltage and current to the grid prescriptions $[3,4,5,6,7,8,9]$.

This paper aims to present in detail a real case scenario of a wind-photovoltaic mini power station (MPS) coupled with a grid connection. This MPS delivers a $220 \mathrm{~V}-50 \mathrm{~Hz}$ electric power and connects to a local grid in case of insufficient power supplied by the MPS [10]. The current injection however is limited to a local confined electrical network because of the local Moroccan regulations. The presented MPS is part of a large smart campus energy management project dedicated to improving energy efficiency and limiting power consumption. The local campus is located at the ENSET institute, Hassan II University of Casablanca Morocco and is the scene for numerous activities targeting HRES integration and advanced energy management $[11,12,13]$.The present work explains the energy management concept used with the HRES in the ENSET campus. Thus the paper starts by presenting the HRES sources and the architectures applied to this case study. The sources models are then presented in order to establish the global energy management system. The study, afterwards, uses real local energy and load data to examine the efficiency and validity of different energy management approaches. However this paper describes a real case study, simulation was used to determine how enhanced energy management algorithms can upgrade the energy management in the campus.

\section{HYBRID PV-WIND SYSTEM ARCHITECTURE}

According to numerous studies, different components can be used as basic sources for the HRES [14, 5, 15, 16, 17]. Their configuration adopts one of the main coupling architectures: DC or AC coupling architecture. The combination of different sources on the same bus poses major problems related to voltage regulation and power distribution. Thus the energy management requires a global optimization of the energy transfer in the HRES using a rigorous analysis of different control methods.

In the DC coupling configuration, all the HRES sources are connected to a common DC bus as shown in Fig. 1. The wind turbine in the one hand is coupled to the DC bus via an AC-DC converter; the photovoltaic panels on the other hand are connected to the same bus using multiple DC/DC converters. The power converters used ensure a proper voltage regulation 
and an optimal power exploitation using the adapted MPPT systems. The power bank is connected to the DC bus through a bidirectional DC-DC converter to maintain a stable storagesupply balance at the rated capacity of the storage units and the optimal control of the DC bus. The charging regulators in the power bank control the charging level of the storage units (Lead-Acid batteries and super-capacitors) and keep an appropriate balance between load demand and power supply. These measures protect the power bank units against deep discharge and high frequency charging-discharging cycles.

In the DC coupling configuration, DC loads can be powered directly from the central DC bus and the AC loads are fed using appropriate DC-AC converters. Furthermore, this configuration, also referred to it as centralized DC-bus topology has proven to be a relatively simple and affordable solution in term of system control. However, numerous studies have reported some disadvantages related to the DC-coupling configuration, like a reduced system efficiency due to the notable energy losses caused by the power converters [18]. The fact also that HRES sources can't power AC loads directly, DC loads being unbalanced are major drag downs for this configuration $[10,16]$.

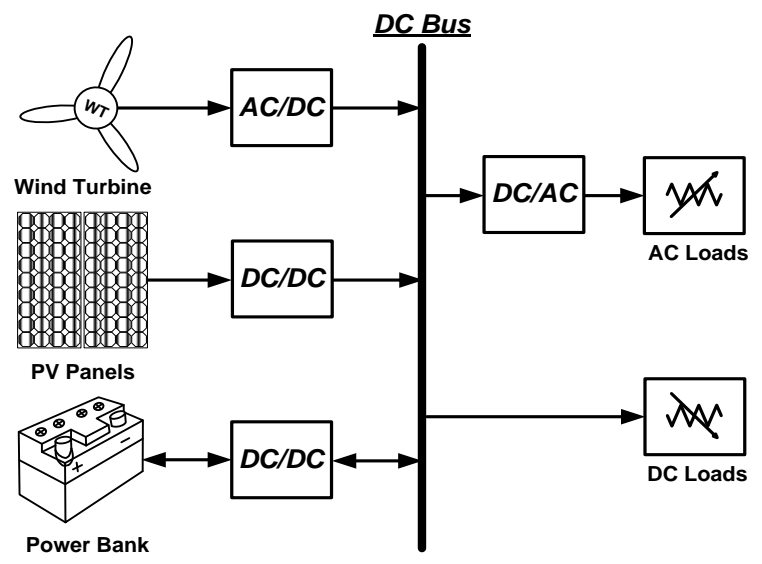

Fig. 1. DC-Coupling Configuration.

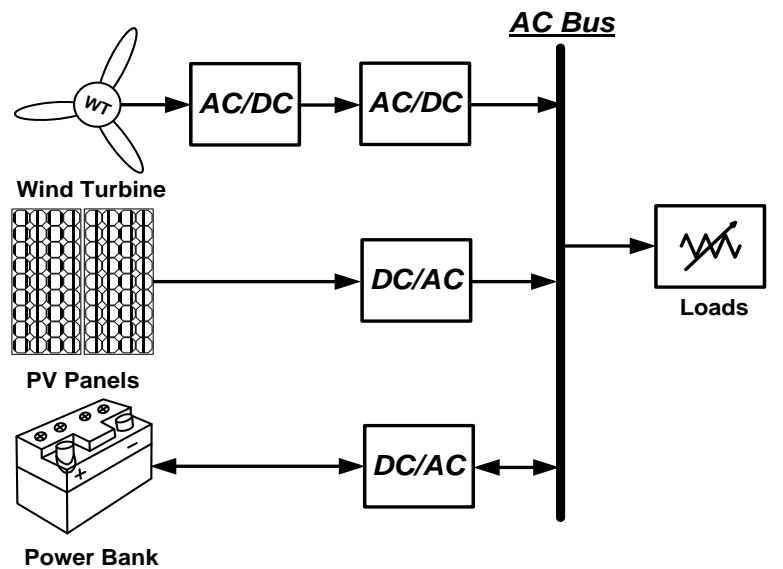

Fig. 2. AC-Coupling Configuration.
In the AC-bus configuration, all renewable energy sources are connected to the main $\mathrm{AC}$ bus via DC-AC or AC-AC converters as shown in Fig. 2. Furthermore the injected AC voltage should be carefully regulated and synchronized taking at consideration the grid prescription. The bidirectional converter used with the power bank regulates the voltage delivered by the power bank and feed the storage units when energy excess is available $[10,16]$. In this architecture, the ACbus is the central component where all the energy is delivered. Thus, it is generally easier to face the energy deficit during peak periods by connecting or disconnecting the grid or an electro-generator. A basic performance comparison of the different bus-coupling architectures should primarily take at consideration the load demand variation during a typical day and how the HRES can cover it. Thus, the AC-coupling configuration is the most efficient one [16]. This configuration is generally adopted for its high reliability, modular and scalable structure, especially when the HRES is off-grid. In the present case, all end-users are AC loads. In addition, the loads are fairly dispatched among different locations, for these reasons the AC-coupling configuration was adopted. The MPS architecture for the present case study is presented in Fig. 3.

All energy sources feed a single AC bus trough appropriate power converters. A $50 \mathrm{~Hz}$ voltage adaption powers the different loads that we categorized into two major sections as it will be detailed further along. To ensure a high reliability of the MPS, the system should possess a minimal probability of power failure. Thus, the grid can feed the AC bus with $230 \mathrm{VAC}-50 \mathrm{~Hz}$ voltage when there is an energy shortage in the HRES. Thus, on normal operating conditions, when there is enough energy, loads are powered using the HRES sources (standalone mode). However, if the load demand exceeds available energy supplied by the HRES sources, loads can draw the needed power out of the power bank if it is possible or the main grid if the storage units are on power outage. The energy excess produced by the HRES is redirected to the power bank to store energy without over charge. These technical needs require an efficient energy management, as proposed further along.

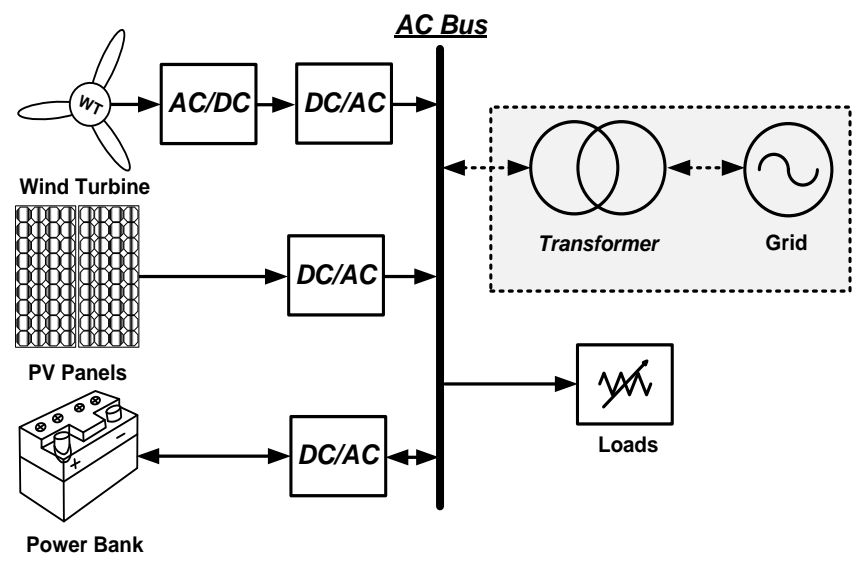

Fig. 3. MPS Architecture. 


\section{HRES MODEL}

Modeling the individual components of each source is first step for sizing a hybrid energy system [19]. This approach can help determine the ideal components characteristics and contribute to the concept of energy management in the MPS.

\section{A. Wind Power Source}

Wind energy is exploited in the ENSET campus using two wind turbines: Whisper 175 and E70 PRO. The characteristics of each turbine are given in Table I.

The energy delivered by the wind turbine can be calculated using the collected wind speed data. Thus, the wind speed output power can be generally calculated using the following equation:

$P_{w}=\frac{1}{2} \cdot C_{p}(\lambda, \beta) \cdot \rho \cdot S_{b} \cdot W_{s}^{3}$

where $\rho$ is the air density $\left(\mathrm{kg} / \mathrm{m}^{3}\right), S_{b}$ is intercepting area of the rotor blades $\left(\mathrm{m}^{2}\right), W_{s}$ is the average wind speed $(\mathrm{m} / \mathrm{s}), C_{p}$ is the power coefficient, a function of tip speed ratio $(\lambda)$ and pitch angle $(\beta)$. The theoretical maximum value of the power coefficient $C_{p}$ is 0.593 , also known as Betz's coefficient. In our case, the pitch angle value is $0^{\circ}$ [20]. The Tip Speed Ratio for a wind turbine is mathematically defined as:

$\lambda=\frac{R \cdot \omega}{W_{s}}$

where $\mathrm{R}$ is radius of turbine ( $\mathrm{m}$ ) and $\omega$ is angular speed $(\mathrm{rad} / \mathrm{s})$. It should be noted that the wind speed at any reference height can be extrapolated to find the wind speed at a different altitude using the following equation [21]:

$\frac{W_{s}(z)}{W_{s}\left(z_{0}\right)}=\left(\frac{z}{z_{0}}\right)^{\alpha}$

Where $W_{\mathrm{s}}\left(\mathrm{z}_{0}\right)$ is the wind speed at the anemometer' height $\mathrm{z}_{0}, \mathrm{~W}_{\mathrm{s}}(\mathrm{z})$ is the wind speed at the height $\mathrm{z}$ and $\alpha$ is a power coefficient relative to the surface roughness.

Furthermore, the total wind turbine energy $E_{w, T}$, during a period $T$, can be calculated using the following equation:

$E_{w, T}=\sum_{i=1}^{n} P_{w, i} \cdot T_{i}$

TABLE I. WIND TURBINES CHARACTERISTICS

\begin{tabular}{|l|l|l|}
\hline \multirow{2}{*}{ Parameter } & Value \\
\cline { 2 - 3 } & Whisper & E70 PRO \\
\hline Peak power (W) & 3200 & 5500 \\
\hline Rate power (W) & 2400 & 4000 \\
\hline Blades numbers & 2 & 3 \\
\hline Blades diameters (m) & 4.26 & 4.3 \\
\hline Cut-in wind speed (m/s) & 3.1 & 2 \\
\hline Rated wind speed & 10 & 11 \\
\hline Voltage (V DC) & $24 / 48$ & $24 / 48$ \\
\hline Tower height $(\mathrm{m})$ & 21 & 14 \\
\hline
\end{tabular}

Where $n$ indicates the number of sampling slot time $T_{i}$ during a large time period such as a month or a year.

\section{B. Photovoltaic Power Source}

The available photovoltaic (PV) power system consists of a multitude of solar panels of different technologies: (i) amorphous technology $\quad\left(\right.$ PowerMax $\left.^{\circledR} 3.5\right)$, (ii) monocrystalline technology $(A C-270 M / 156-60 S)$, and (iii) polycrystalline technology $(A C-270 P / 156-60 S)$. Table II summarizes the main parameters of the used PV panels at Standard Test Conditions STC (Air Mass AM1.5, Irradiance $1000 \mathrm{~W} / \mathrm{m}^{2}$, Cell Temperature $25^{\circ} \mathrm{C}$ ):

Mathematic modeling of the physical phenomena behind the PV system behavior is a critical to establish a well-founded energy management concept. As widely discussed in a large number of papers $[19,22,23]$, the mathematical equation describing the current-voltage characteristic of a PV cell is given by the implicit model using a single or double diode. In this case, the single diode model was adopted as represented in Fig. 4. We carefully adopted the same parameters as given by the PV constructor.

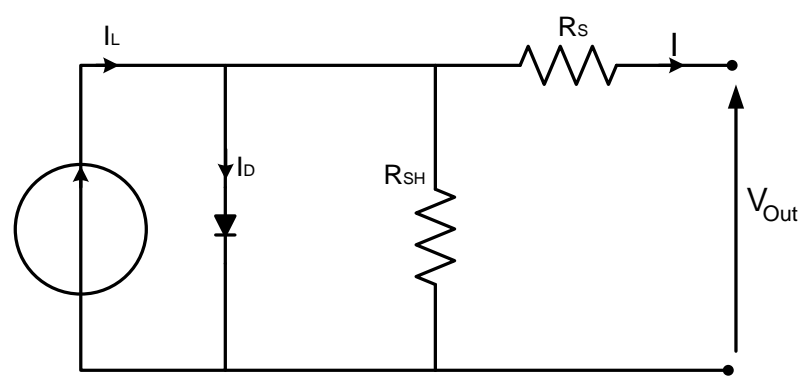

Fig. 4. Single Diode PV Model.

TABLE II. SOlAR PANELS CHARACTERITICS

\begin{tabular}{|c|c|c|c|}
\hline \multirow{2}{*}{ Parameter } & \multicolumn{3}{|l|}{ Value } \\
\hline & $\begin{array}{l}\text { PowerMax } \AA \\
3.5\end{array}$ & $\begin{array}{l}A C-270 M / 156- \\
60 S\end{array}$ & $\begin{array}{l}A C-270 P / 156- \\
60 S\end{array}$ \\
\hline $\begin{array}{l}\text { Maximum power } \\
\text { Pm }\end{array}$ & $125 \mathrm{Wc}$ & $270 \mathrm{Wc}$ & $270 \mathrm{Wc}$ \\
\hline $\begin{array}{l}\text { Current at maximum } \\
\text { power point Impp }\end{array}$ & $2.981 \mathrm{~A}$ & $8.80 \mathrm{~A}$ & $8.71 \mathrm{~A}$ \\
\hline $\begin{array}{l}\text { Voltage at maximum } \\
\text { power point Vmpp }\end{array}$ & $42.4 \mathrm{~V}$ & $30.94 \mathrm{~V}$ & $31.12 \mathrm{~V}$ \\
\hline $\begin{array}{l}\text { Short-circuit current } \\
\text { Isc }\end{array}$ & $3.35 \mathrm{~A}$ & $9.41 \mathrm{~A}$ & $9.25 \mathrm{~A}$ \\
\hline $\begin{array}{l}\text { Open circuit voltage } \\
\text { Voc }\end{array}$ & $58 \mathrm{~V}$ & $39.26 \mathrm{~V}$ & $38.21 \mathrm{~V}$ \\
\hline Panel efficiency & $11.9 \%$ & $16.6 \%$ & $16.6 \%$ \\
\hline $\begin{array}{l}\text { Current temperature } \\
\text { coefficient } \alpha s c\end{array}$ & $0 \mathrm{~mA} /{ }^{\circ} \mathrm{C}$ & $0.04 \% / \mathrm{K}$ & $0.04 \% / \mathrm{K}$ \\
\hline $\begin{array}{l}\text { Voltage temperature } \\
\text { coefficient } \beta \text { oc }\end{array}$ & $-170 \mathrm{mV} /{ }^{\circ} \mathrm{C}$ & $-0.3 \% / \mathrm{K}$ & $-0.3 \% / \mathrm{K}$ \\
\hline $\begin{array}{l}\text { Temp. Coefficient of } \\
\text { Powerkp }\end{array}$ & $-0.39 \% /{ }^{\circ} \mathrm{C}$ & $-0.4 \% / \mathrm{K}$ & $-0.42 \% / \mathrm{K}$ \\
\hline
\end{tabular}


The mathematical equation combining the cell voltage $V_{c}$ and cell current $I_{C}$ is amply described in [19] and can be expressed as:

$I_{c}=I_{p h}-I_{s 1} \cdot\left[\exp \left(\frac{V_{c}+R_{s c} I}{a_{1} V_{T 1}}\right)-1\right]-\frac{V_{c}+R_{s c} I}{R_{p c}}$

The PV cell generated current is noted $\mathrm{I}_{\mathrm{ph}}, \mathrm{I}_{\mathrm{s} 1}$ and $\mathrm{I}_{\mathrm{s} 2}$ are the reverse saturation current of the model's diode, $\mathrm{V}_{\mathrm{T} 1}$ isthe diode thermal voltage, $a_{1}$ represents thediode ideality constant. $R_{s c}$ and $R_{p c}$ are respectively the series loss resistance and shunt loss resistance of the cell. The output power of a PV cell is given by the following equation:

$P_{c}=V_{c} \cdot I_{c}$

To enhance the power, the PV array consists of $N_{s}$ and $N_{p}$ PV cells connected in series and parallel respectively. Therefore, the total power output for the global array will be:

$P_{\text {array }}=N_{s} \cdot N_{p} \cdot P_{c}$

The output power of the PV module is primarily related to the solar radiation and the ambient temperature. Thus, the output power of the PV array $(\mathrm{kW})$, denoted $P_{P V}$, is given by:

$P_{P V}=P_{R} \cdot f_{P V} \cdot \frac{G_{T}}{G_{S T C}} \cdot\left[1+k_{p} \cdot\left(T_{C}-T_{S T C}\right)\right]$

Where $P_{R}$ is the rated power of the PV moduleunder standard test conditions (kW), $f_{P V}$ is the PV derating factor, $G_{T}$ the solar radiation $\left(\mathrm{kW} / \mathrm{m}^{2}\right), G_{S T C}$ incident radiation at standardtest conditions $\left(1 \mathrm{~kW} / \mathrm{m}^{2}\right), k_{p}$ the temperature coefficient $\left(0.004^{\circ} \mathrm{C}^{-1}, T_{C}\right.$ the $\mathrm{PV}$ cell operation temperature $\left({ }^{\circ} \mathrm{C}\right)$ and $T_{S T C}$ is $\mathrm{PV}$ cell temperature under standard test conditions $\left(25^{\circ} \mathrm{C}\right)[24]$.

\section{POWER BANK}

In order to achieve a reliable and efficient HRES, a power bank system is used to ensure continuous delivery of power to the loads. The storage system is used as a backup option to store energy when there is a production excess. The power bank is specifically designed to supply power when wind speed and solar radiation are weak or during peak hours when there is a high demand of energy. This study uses a battery-super capacitors hybrid energy storage system (BSHS). Batteries are the primary energy buffer for long durations and normal exploitation, Super-capacitors provide energy during instantaneous massive power demand. This design is supposed to help HRES keep a stable output and meet sudden peak power consumption.

\section{A. Lead-Acid Batteries}

Batteries modeling and for energy management purpose it relies on the determination state of charge (SOC) during exploitation. This criterion is a fundamental key in optimizing energy management and batteries lifetime cycles. Modeling the lead acid batteries used in the HRES $[25,26]$ should take at consideration the internal parameters of batteries such as the state of charge (SOC), storage capacity, the rate of charge/discharge, ambient temperature and the life cycle [26, $27,28]$.
All battery circuit parameters are widely described in [23], where an equivalent circuit of the battery is represented. The SOC being the most important parameters of theme all, it is generally calculated between a starting time $t_{0}$ and the time of study $t$ and is given by [24]:

$S O C=S O C_{0}+\int_{t_{0}}^{t}\left(\frac{I_{b a t}}{C_{b a t}}\right) d t$

where $S O C_{0}$ is the battery's state of charge at the starting time, $\mathrm{C}_{\text {bat }}$ is the battery capacity $(\mathrm{Ah})$ and $I_{\text {bat }}$ is the battery current (A).However, in order to preserve the battery's health, theSOC is generally subjected to the following constraints [24]:

$S O C_{\min } \leq S O C(t) \leq S O C_{\max }$

Where $S O C_{\min }$ and $S O C_{\max }$ are the minimum and maximum allowable battery charge. Here the $S O C_{\max }$ is the rated nominal capacity of battery bank $\left(C_{b a t}\right)$ and $S O C_{\min }$ is determined by depth of discharge (DOD), as described in the following equation:

$S O C_{\min }=\left(1-D O D_{\max }\right) \cdot C_{b a t}$

$D O D_{\max }$ is the maximum allowable depth of discharge which may decrease battery life [24, 26]. It should be noted that SOC can't be measured directly, but can be estimated as detailed in [29, 30].

\section{B. Super-Capacitors (SC)}

Super-capacitors are components able to store energy directly as electric charges, contrary to batteries storage process which is based on chemical reactions. The supercapacitors have a higher power density compared to batteries and provide high power over a short time lapse. Furthermore, super-capacitors-based storage systems possess longer life cycles and are ideally suited for high power and short discharge applications [14, 31]. Several representative models of super-capacitors have been introduced in literature [23]. However, the classic equivalent circuit for the super-capacitor highlight the effect of the capacitance $(C)$, the equivalent series resistance $\left(R_{E S}\right)$, and the equivalent parallel resistance $\left(R_{E P}\right)$ $[23,32,33]$. The total usable energy from a SC is given by:

$E_{S C}=\frac{1}{2} \cdot C_{t} \cdot\left(V_{i}^{2}-V_{f}^{2}\right)$

Where $V_{i}$ and $V_{f}$ are respectively the initial voltage before the discharging starts and the final voltage after the discharging ends; $C_{t}$ is the total SC system capacitance. $C_{t}$ can be the equivalent of series or parallel combination of capacitors. $C_{t}$ is given by:

$C_{t}=\frac{n_{p}}{n_{s}} . C$

Where, $n_{s}$ is the number of SCs connected in series to meet the rated $D C$ voltage and $n_{p}$ is the number of SCs connected in parallel to achieve the required storage capacity.

\section{Hybrid Power Storage Approach}

Using both batteries and super-capacitors in the power bank can enhance its performance. Thus, batteries are generally used to exploit the long term storage capability and super-capacitors 
are combined during certain time laps where important loads are detected. The Batteries/Super-capacitors coupling can be configured in different ways [34, 35]. The architecture of coupling in the present work is represented in Fig. 5. This configuration uses two bidirectional $D C / D C$ converters and a $D C / A C$ converter for the $A C$ bus interfacing. Furthermore, this configuration guaranties a flexible control of the power bank during power failure.

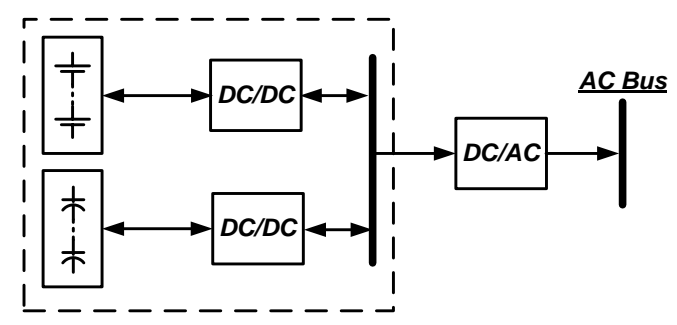

Fig. 5. Batteries-Supercapacitors Hybrid Coupling.

For the study in this paper, the batteries/super-capacitors hybrid system is composed of 6 batteries with different coupling possibilities $(12 \mathrm{~V}, 210 \mathrm{AH}, 1500 \mathrm{~A})$ and 20 Supercapacitors (1200 F, 2.7V, 1.2Wh).

\section{ENERGy Potential AsSESSMENT AND LOAD VARIATION}

The studied case in this paper was carried out, taking at consideration the wind and solar data provided by a meteorological station installed at the ENSET instituteMohammedia, Morocco (location: 3341'23” N, 7²3'23” W) [21]. The wind speed and solar radiation data for a typical day used to simulate HRES architecture performance and energy management options are respectively shown in Fig. 6 and 7.

The load variation is represented by a real case scenario of the ENSET institute. All information about heating, lightening, teaching and other electrical power consumption within the administrative department was carefully collected in order to simulate different scenarios.

Energy consumption in the institute is directly affected by the teaching activities, thus there is a noticeable decrease in power consumption during the July-September holiday period. The evaluated loads in this work are based on the campus buildings architecture. These blocks are named Block 1 to Block 6. Power Consumption is evaluated based on the time period when each block draws energy.

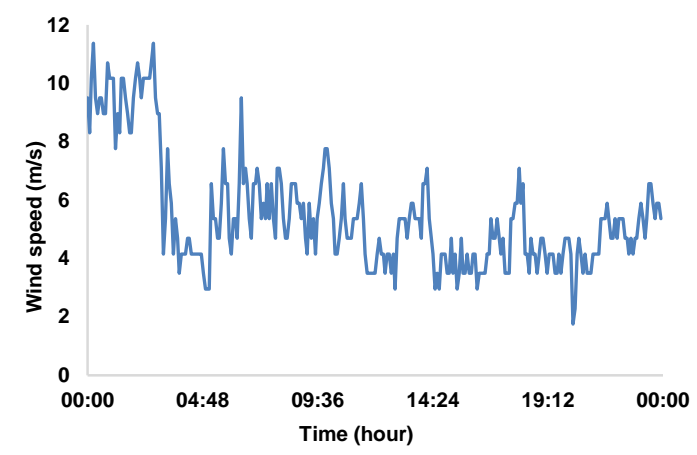

Fig. 6. Wind Speed Data for a Typical Day.

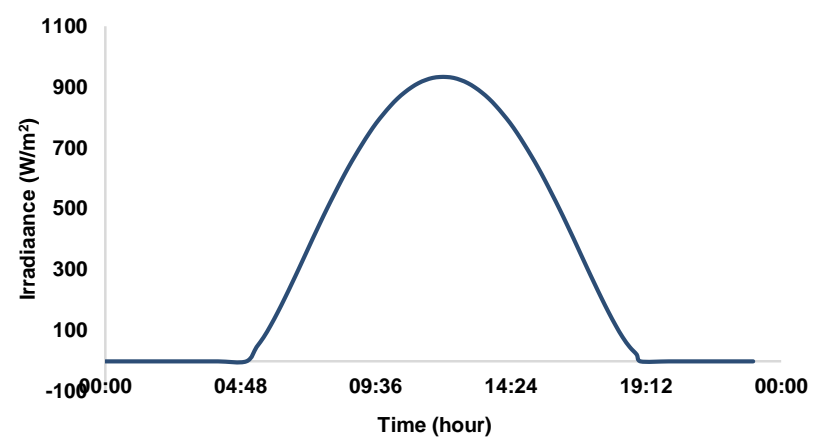

Fig. 7. Solar radiation Data for a Typical Day.

\section{ENERGy MANAGEMENT SySTEM}

\section{A. Strategy Description}

The power supplied by renewable energy sources can't be ensured continuously, the proposed HRES must include an integrated energy management system (EMS) to allow an optimal power supply as well in off-grid mode as in gridconnected mode. When the system is operating in off-grid mode, renewable energy sources and the power bank act as the primary source of energy. The grid, however, can always supply additional power when there is a shortage in the HRES. Thus, energy can either be absorbed by the HRES or injected into the grid, if the load power demand and conditional requirements are met. The primary objective is to ensure that the HRES feed the local loads using available renewable energy sources and minimizing the grid contribution as much as possible.

The main decision parameters for the power management strategies are the available instantaneous power from the renewable energy system (wind-sun), the instantaneous state of charge $\left(S_{O} O C_{C}^{B}(t)\right)$ of the power bank and the load profile. Thus, the instantaneous available power $\left(P_{a v}(t)\right)$ provided by the hybrid system is defined as:

$P_{a v}(t)=P_{w}^{G}(t)+P_{p v}^{M}(t)+c \cdot P_{C}^{B}(t)$

$P_{w}^{G}(t)$ is the power provided by the two wind turbine systems:

$P_{w}^{G}(t)=P_{w 1}(t)+P_{w 2}(t)$

$P_{p v}^{M}(t)$ denotes the total power delivered by the PV modules:

$P_{p v}^{M}(t)=\sum_{i=1}^{n} P_{p v_{i}}(t)$

$P_{C}^{B}(t)$ is the supplied or absorbed power according to the BSHS discharging or charging process respectively according to the $c$ value:

$c \in[-1,1]$

Expression (17) means:

$\left\{\begin{array}{l}c=-1 \Leftrightarrow \operatorname{SOC}_{C}^{B}(t)=S O C_{\min }^{B C} \\ c=1 \Leftrightarrow S O C_{C}^{B}(t)=S O C_{\max }^{B C} \\ -1<c<1 \Leftrightarrow S O C_{\min }^{B C}<S O C_{C}^{B}(t)<S O C_{\max }^{B C}\end{array}\right.$ 
The case (17.1) and case (17.2) represents respectively the charging and discharging process of the Power bank units. However, in the case (17.3), the hybrid storage units provide or absorb energy to maintain a minimal consumption from the grid. The instantaneous total loads power $\left(P_{L}^{T}(t)\right)$ delivered by the sources can be expressed as:

$P_{L}^{T}(t)=f \cdot P_{a v}(t)+(1-f) \cdot P_{G}(t)$

Where $P_{G}(t)$ is the grid power and $f$ the portion of loads supplied by the HRES system $(0 \leq f \leq 1)$. For example, when $f=1$, the HRES sources supply the total requested power. Otherwise, if $f=0$, the totality of the needed power is delivered by the grid.

In the proposed energy management system (EMS), it is possible to connect or disconnect the loads according to the available power of the HRES and Power Bank. Mainly, the energy management algorithm is made to achieve the followings objectives:

- Providing an instantaneous power supply adapting the generated energy to the loads.

- Minimizing the use of the grid.

- Improving the performance of the system by optimizing the use of the Power Bank and avoiding its critical solicitation.

It should be noted that the super capacitor has a faster charge/discharge speed. Thus, this component is less sensitive to high frequency charging cycles. The super capacitors are then the first components to be connected in order to minimize the involvement of batteries as much as possible. The different principles of this approach are described in the following flow chart in Fig. 8.

Furthermore different types of loads have to be managed according to the available HRES power. In order to achieve this goal, a Load Management Module (LMM) was carefully elaborated. The LMM approach is based on the basic principal of load prioritizing; this means that powering a load doesn't only depends on the maximum available energy of the HRES and power bank status, but also on the priority of the targeted load. Thus, the end-use loads are categorized into two major types: primary and secondary appliance. The primary loads are critical. Therefore, they have to be powered without any shifting in time. This type is given a higher priority and is allowed to operate at its scheduled time. The secondary appliance type however, can be shifted in time because the nature of the use doesn't require an immediate powering.

if each primary load $F l_{i=1,2, \ldots, n}$, of a building block $B_{b=1,2, \ldots, 6}$, has a rated power $P_{i, b}^{F l}$ then the total power of the $\mathrm{n}$ fixed loads $\left(P_{L}^{F}(t)\right)$, in a time t of the day, is expressed by:

$P_{L}^{F}(t)=\sum_{b=1}^{6}\left(\sum_{i=1}^{n} P_{i, b}^{F l}(t) \times s_{i, b}^{F l}(t)\right)$

Where $s_{i, b}^{F l}(t)$ is the state of $F l_{i=1,2, \ldots, n}$ for each block B in slot time $t$ :

$s_{i, b}^{F l}(t)=\left\{\begin{array}{l}1 \text { if the load is powered } \\ 0 \text { if the load is not powered }\end{array}\right.$

Likewise, the total power consumption of all secondary loads $\left(P_{L}^{S}(t)\right)$ taking as consideration the state of each component, is calculated using the following equation:

$P_{L}^{S}(t)=\sum_{b=1}^{6}\left(\sum_{j=1}^{j} P_{j, b}^{S l}(t) \times s_{j, b}^{S l}(t)\right)$

The instantaneous total power of $\operatorname{loads}\left(P_{L}^{T}(t)\right)$, written on equation (18), can also be expressed by:

$P_{L}^{T}(t)=P_{L}^{F}(t)+P_{L}^{S}(t)$

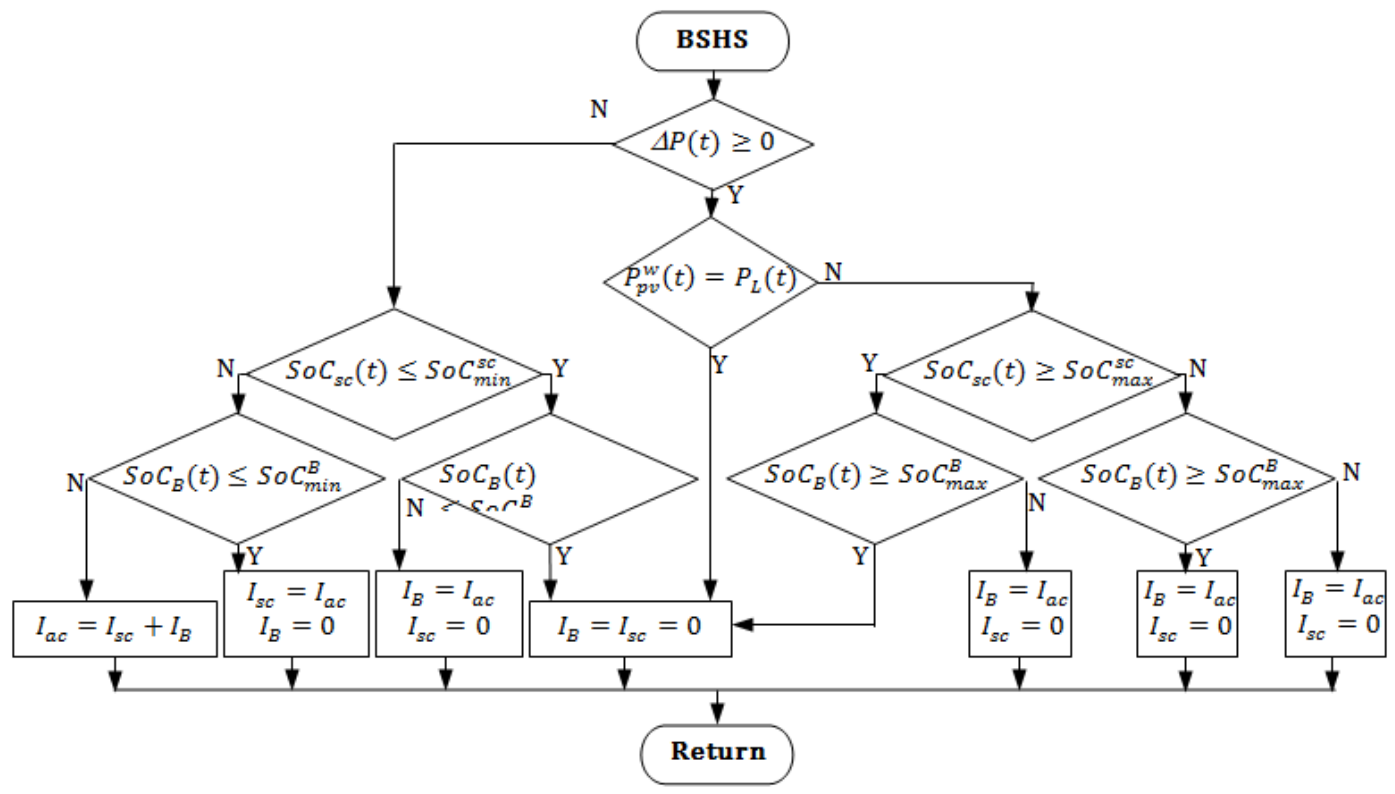

Fig. 8. Power Bank Management based on SoC Control. 
Based on this approach, after supplying the primary loads with the required power, the LMM module, should supply as much energy as possible to the secondary loads. In order to achieve this function, the LMM module compares the excess of energy to the required power from secondary loads and disconnects their elementary units until the achievement of balance between the supplied power and total load demand. The following algorithm explains how exactly the LMM module works.

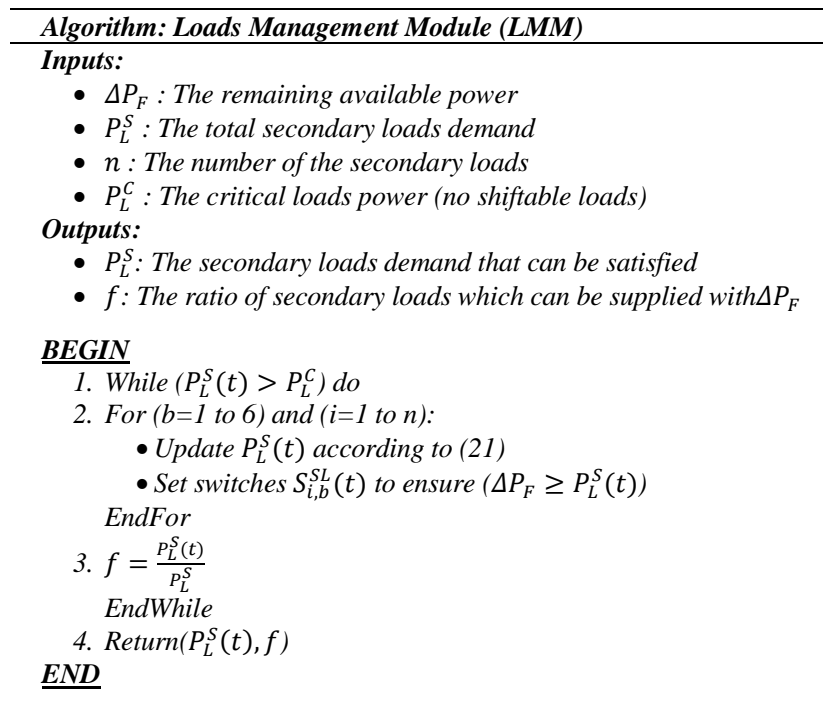

Flowchart of the global energy management is represented in Fig. 9 in order to describe the general functioning of the system.

The global management algorithm basically calculates the total available renewable energy, if it is possible to supply both primary and secondary appliance loads, the power management system connects all loads. In the case of power shortage (when renewable energy can't cover the total energy demand) the LMM disconnects a certain number of secondary loads until achieving the appropriate balance between available energy and load demand $\left(\Delta P_{F}(t) \geq P_{L}^{S}(t)\right)$. However, when available renewable energy doesn't even cover the primary load, the energy deficit should be drawn from the grid according to (18). This approach ensures a continuous and uninterruptible supply to the primary load whose functioning is fundamental.

\section{B. System Modeling and Strategy Simulation}

In order to study this strategy in details and determine which strategy scenario is the best in terms of efficiency and functionality, each component of the global energy system has been carefully modeled according to the real data collected from the ENSET campus. Fig. 10 illustrate the global modeled system

As it can be noticed in Fig. 10, six major blocks have to be modeled in order to state about the energy management strategies. The first block represents the power generated from the wind turbine. A physical approach has been adopted in order to simulate the available wind power. Thus, in the wind power energy block, wind turbines, $A C / D C, D C / A C$ and MPPT converters have been used. However, the generated power is conditioned by the available wind potential. In the photovoltaic power source, PV panels, MPPT and $D C / A C$ converters have been used. The power delivered by the PV panels is also subject to the sun irradiation data collected. The power Bank was simulated using models of Lead-Acid batteries and super-capacitors, in addition the $D C / D C$ and $D C / A C$ converters adapt the delivered voltage. The power delivered by the power bank is conditioned by the $S o C$. Thus, when the $S o C$ is below $20 \%$, power is drowning from the grid when the HRES are in shortage. Above $80 \%$ power is injected into the grid if there is an excess. Loads also have been modeled using the campus data collected from the concerned building. Furthermore, the grid has been modeled to supply or absorb power depending on the situation if there is an energy shortage or excess. Finally, the energy management system is responsible of finding the best strategy for managing power demand and energy generation. Fig. 11 presents the simulation diagram including the hybrid renewable energy sources, the power bank, the loads and the AC bus where different scenarios of energy management can be injected.

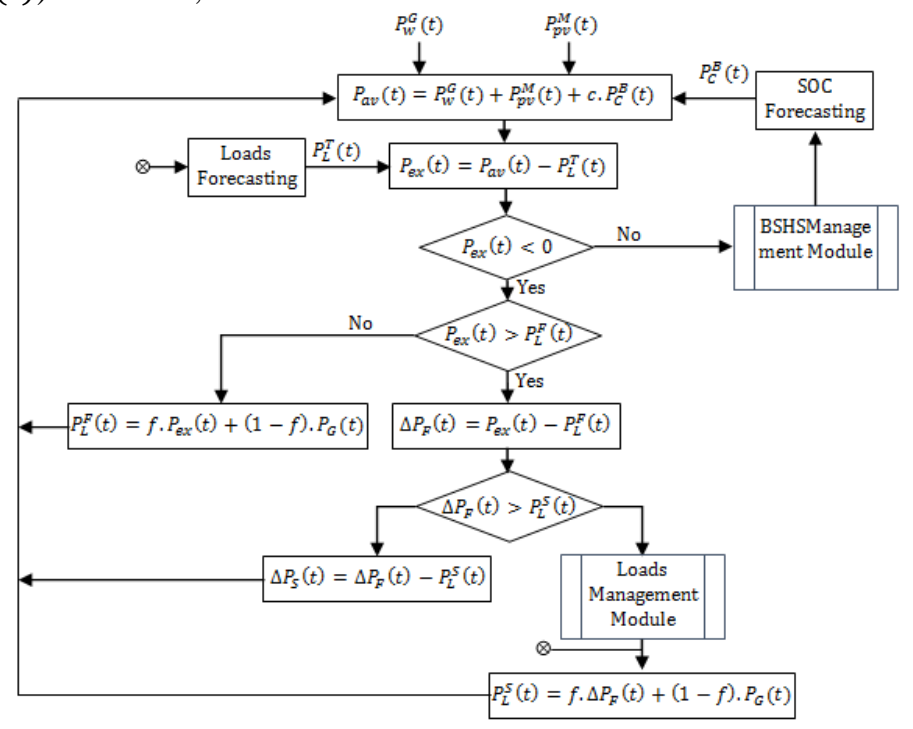

Fig. 9. Basic Flowchart of the Global Energy Management. 


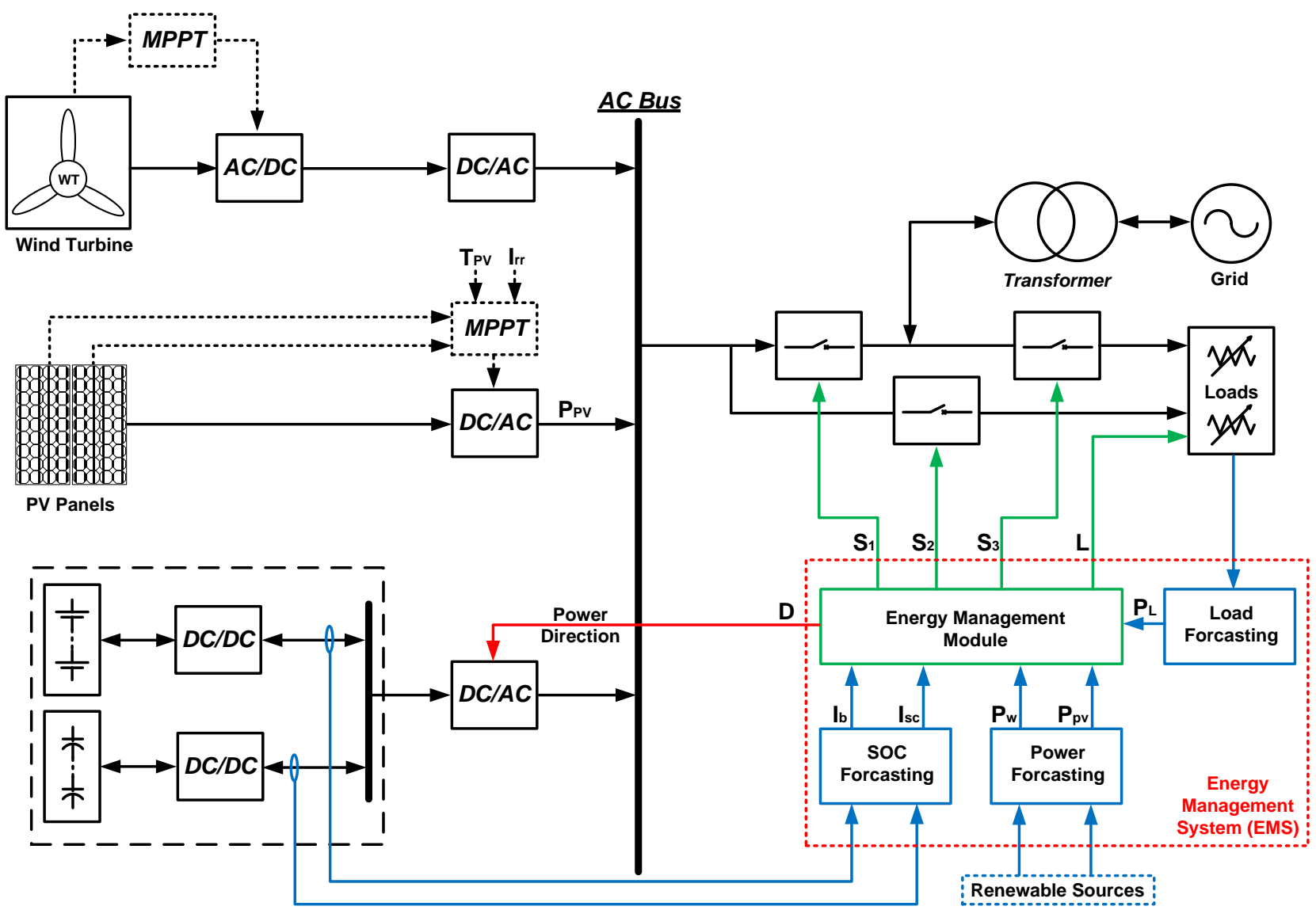

Fig. 10. Global Model of the Studied System.
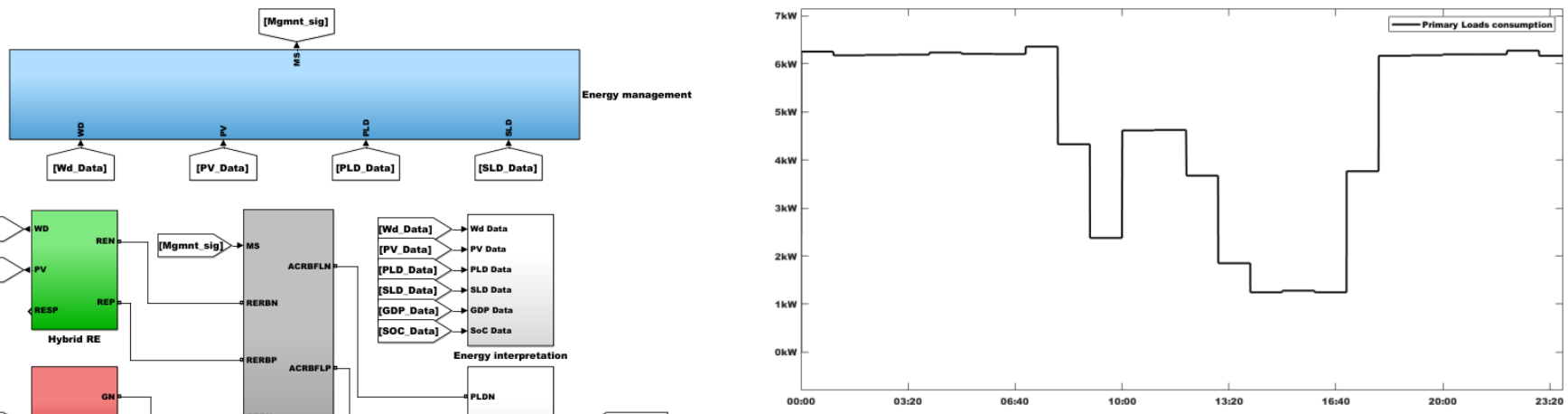

Fig. 12. Primary Load Evolution Supply During a Typical Week-end Day.

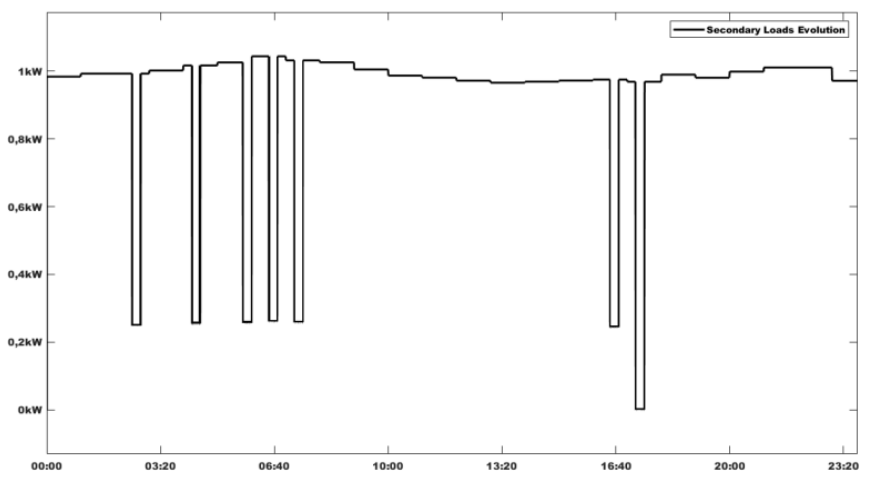

Fig. 13. Secondary Load Evolution Supply During a Typical Week-end Day. 
As it can be noticed on Fig. 12 and 13, primary loads are always powered whatever are the sources conditions, due to the criticality of the loads. Secondary loads however are disconnected when there is an energy shortage. Fig. 14 and 15 present respectively the quantity of power generated by Photovoltaic Panels and Wind Turbines.

Data used for simulating delivered power by the HRES was carefully collected on the campus during one year. The power presented in Fig. 14 and 15 is for a typical day using the load data in the buildings. Fig. 16 presents the global power generated by the HRES sources and the energy demand of the loads.

In Fig. 16, the black curve represents the total power generated by both sources PV panels and wind turbines. Green curve represents the power delivered to the secondary loads and the blue line represents the power delivered to the primary load. The red curve is the total power delivered to both loads, thus when the black curve is above the red one, there is enough energy within the HRES to supply both secondary and primary loads. However when the total energy demand is above the available power in the HRES, energy is withdrawn from the Grid. Fig. 17 presents the periods when energy is supplied by the grid.

In order to optimize the energy consumption within the campus, excess of energy generated by the HRES sources should be injected back to Grid when the Power Bank reaches the maximum storage capacity. Fig. 18 presents the energy exchange in the energy management system.

When the energy is below 0 (red line), power is withdrawn from the Grid. However when there is enough energy to cover the total load needs (power curve above 0), the energy excess is injected into the grid. For example, we can clearly see in Fig. 18 that on the middle of the day when both PV and wind potential are available, no power is withdrawn from the grid; however, it supplies most of energy during the first part of the night. The switching of the primary source is a very crucial aspect in the proposed energy management system. Therefore, the Power Bank helps diminishing the frequency of energy source switching, by providing an alternative during short periods of energy demand or temporary HRS disconnection. It is also the main destination where energy is routed before achieving energy excess.

Energy cost is also a key component in the energy management algorithm. Based on Fig. 16, it can be noticed that the secondary loads represented by the green curve are generally almost constant through the day. These loads represent routine work tasks that can be done at any time, automatically by machines or manually using electric tools. Thus these tasks can be shifted to any period of the day without any alteration. The management algorithm can help avoiding unnecessary power consumption during Peak hours. Thus it postpones the task when the not enough power available or when eminent power demand is about to start (power forecasting). Furthermore, the Power Bank is strictly reserved to the primary loads in order to avoid unnecessary energy dissipation. This goes against classic renewable energy systems where generally the Power Bank is not strictly controlled and is used in all energy routing.

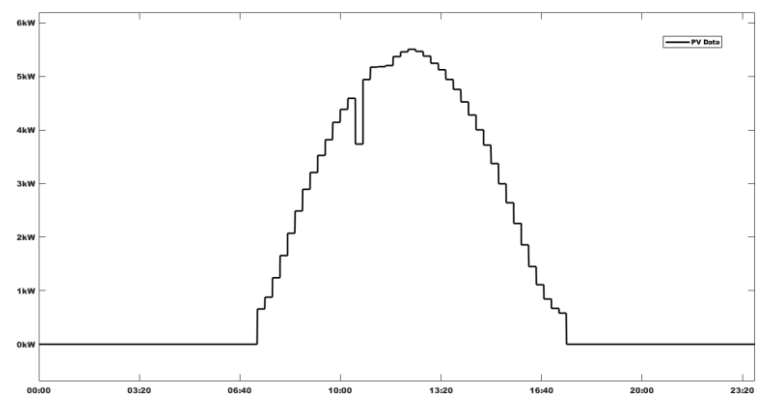

Fig. 14. Power Delivered by the Photovoltaic Panels.

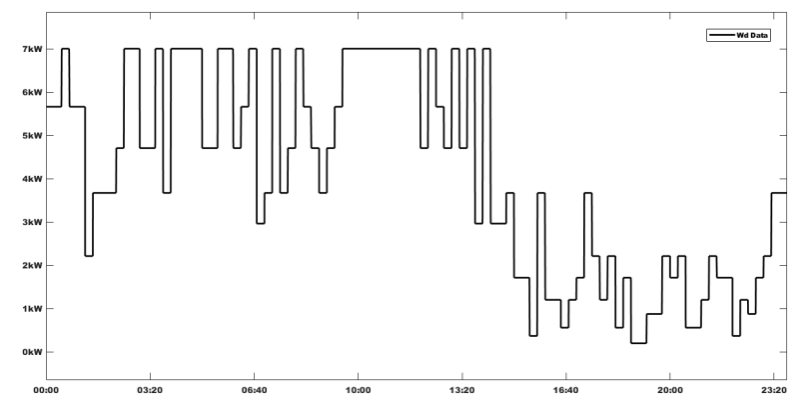

Fig. 15. Power Delivered the Wind Turbines.

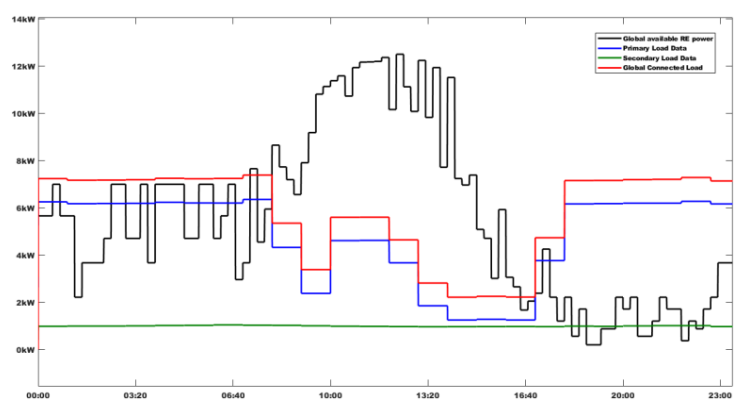

Fig. 16. General Energy Flow in the Hybrid Renewable Energy Station.

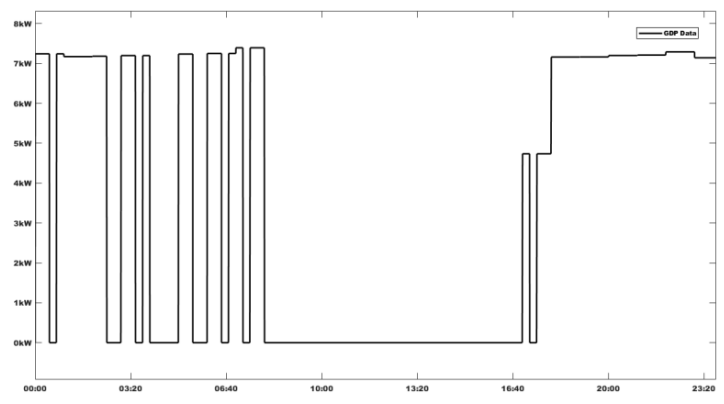

Fig. 17. Energy Supplied by the Grid.

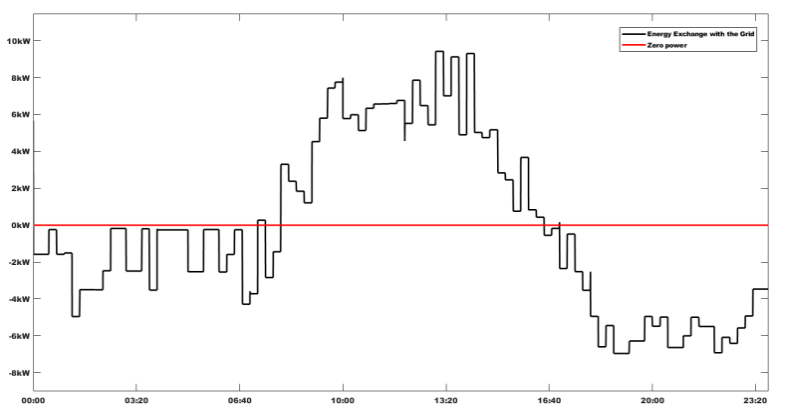

Fig. 18. Grid Energy Exchange During a Typical Week-end Day. 
b) Typical working day scenario: On a typical working day scenario the global connected load is much more important. Fig. 19 represents the total connected load during typical working days. As it can be noticed in Fig. 19, power consumption on working days are much more important due to an excess of connected loads. Unlike the week-end scenario, during working days, secondary loads are not disconnected due to necessity of the constant use of the grid. However, a more economical approach can be achieved by disconnected as many secondary loads as possible on peak consumption period when power price is higher. Fig. 20 represents the global results obtained during a typical working day. The difference in the available energy during the day was taken into consideration, thus the wind and radiation data is from a different day.

It can be clearly noticed that the available sources in the campus are insufficient for covering the total load demand, especially in the middle of the day. In order to minimize the grid use, the available HRES should be used to compensate the energy drawn from the grid. Fig. 21 presents the energy exchange with grid.

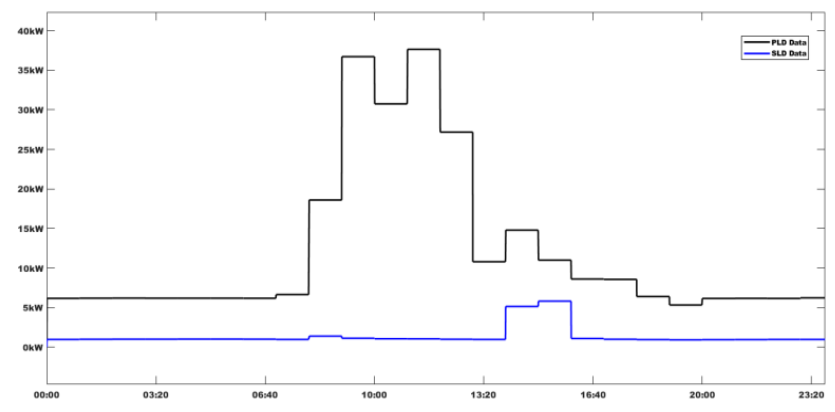

Fig. 19. Total Loads Evolution During a Typical Working Day.

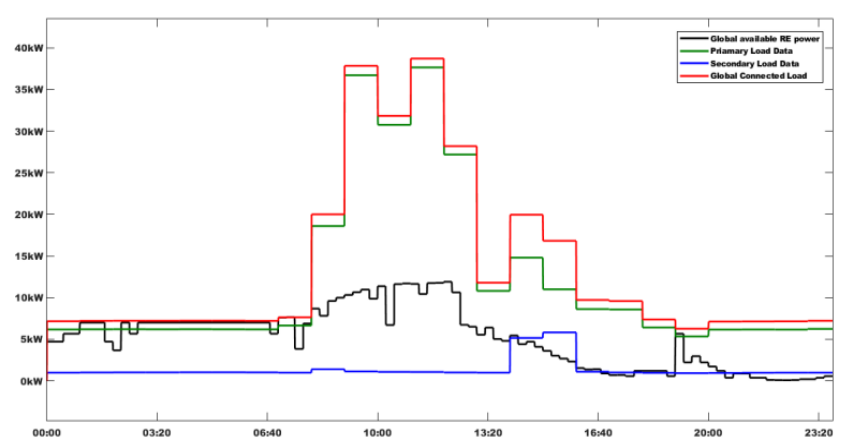

Fig. 20. Global Energy Flow During a Typical Working Day.

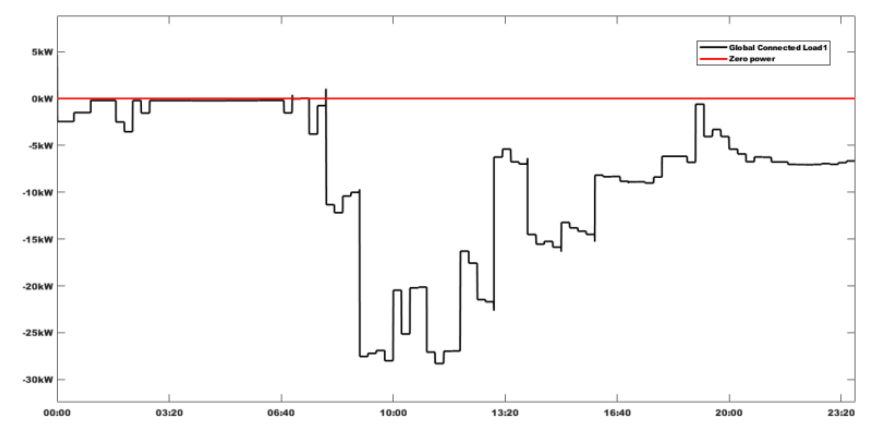

Fig. 21. Grid Energy Exchange During a Typical Working Day.
Because of the important load, on a typical working day, most of the energy is drawn from the grid. However the HRES helps reducing the grid's dependency. Nevertheless, the available wind and solar potential are fairly sufficient for covering the campus by upgrading the available HRES sources. The available wind potential can accommodate wind turbines ranging up to $12 \mathrm{~kW}$. This measure, along with a more important solar potential, can cover the global energy consumption of the campus, realizing consequently a standalone power status. In the meanwhile, energy consumption optimization can only targets loads categorization, energy exchange with the grid and power compensation in special cases.

\section{VII.CONCLUSION}

In this paper, we analyzed the energy management in a hybrid renewable energy station. Models of each source including wind turbines, PV panels and the Power Bank have been presented in detail. Actual data has been collected in order to model the PV panels, wind turbines and loads in the different buildings. Then, the energy management algorithm has been explained in detail. The main role of the proposed system is to exploit the hybrid renewable energy sources as much as possible. Thus most of the energy is taken from the hybrid renewable sources and the Power Bank is used to accommodate short periods of energy decrease. However when there is an energy shortage prediction the loads are mainly powered using the grid. The actual collected data was implemented on a simulation environment to validate the energy management scenarios. Results have shown that using this technique can help retrieving the small energy quantities during extended period of loads exploitation. To resume, the basic energy has to be extracted from renewable energy sources, the algorithm helps detecting period of times when the Power Bank can help overcome the energy shortage. However, as last resort when it is not possible for the power bank to cover the whole period, the loads are connected to the grid according to their types and criticality. The present approach was mainly based on loads categorizing; two groups of loads (Primary and secondary) were introduced. We intend, in upcoming works to manage energy in the same campus building from a different standpoint, where each load can have a different prominence coefficient depending on the day, appliance and continuity of use.

\section{REFERENCES}

[1] Omar Ellabban, Haitham Abu-Rub, FredeBlaabjerg, "Renewable energy resources: Current status, future prospects and their enabling technology", Renewable and Sustainable Energy Reviews,39748-764, (2014). DOI: 10.1016/j.rser.2014.07.113

[2] Binayak Bhandari, Shiva Raj Poudel, Kyung-Tae Lee, Sung-HoonAhn, "Mathematical Modeling of Hybrid Renewable Energy System: A Review on Small Hydro-Solar-Wind Power Generation", International Journal of Precision Engineering and Manufacturing-Green Technology, Vol. 1, No. 2, pp. 157-173, (2014), DOI: 10.1007/s40684-014-0021-4

[3] R. Luna-Rubio, M. Trejo-Perea, D. Vargas-Vázquez, and G. J. RíosMoreno, "Optimal sizing of renewable hybrids energy systems: A review of methodologies" Solar Energy, 86, 1077-1088 (2012), DOI: 10.1016/j.solener.2011.10.016

[4] M. Dali, J. Belhadj, X. Roboam, "Hybrid Solare-wind system with battery storage operating in grid-connected and standalone mode: Control and energy management-Experimental investigation", Energy, 35 (2010) 2587-2595. DOI:10.1016/j.energy.2010.03.005 
[5] P. G. Arul, V. K. Ramachandaramurthy, and R. K. Rajkumar, "Control strategies for a hybrid renewable energy system: A review", Renewable and Sustainable Energy Reviews, 42, 597-608, (2015), DOI: 10.1016/j.rser.2014.10.062

[6] B. Bhandari, K. T. Lee, G. Y. Lee, Y. M. Cho, and S. H. Ahn, "Optimization of hybrid renewable energy power systems: A review" International Journal of Precison Engineering and Manufacturing Green Technology, 2, 99-112 (2015) DOI:10.1007/s40684-015-0013-z

[7] Rashid Al Badwawi, Mohammad Abusara, Tapas Mallick, "A Review of Hybrid Solar PV and Wind Energy System", Smart Science, Vol.3, No. 3, 127-138 (2015), DOI:10.1080/23080477.2015.11665647

[8] Tajeddine, K., Abdelhadi, R., Omar, B., \& Hassan, O. (2017). A Cascaded H-Bridge Multilevel Inverter with SOC Battery Balancing. INTERNATIONAL JOURNAL OF ADVANCED COMPUTER SCIENCE AND APPLICATIONS, 8(12), 345-350.

[9] TajEddine, K, Abdelhadi, R., Omar, B., \& Hassan, O. (2018, April). A new multilevel inverter with genetic algorithm optimization for hybrid power station application. In 2018 4th International Conference on Optimization and Applications (ICOA) (pp. 1-6). IEEE.

[10] T.S. Ustun, C. Ozansoy, A. Zayegh, "Recent developments in microgrids and example cases around the world-A review",Renewable and Sustainable Energy Reviews, 15 (2011) 4030-4041. DOI: 10.1016/j.rser.2011.07.033

[11] H.R. Ghosh, S.K. Nandi, "Techno-economical analysis of off-grid hybrid systems at Kutubdia Island, Bangladesh", Energy Policy,38(2):976-80 (2010).DOI: 10.1016/j.enpol.2009.10.049

[12] B.Y. Ekren, O. Ekren "Simulation based size optimization of a PV/wind hybrid energy conversion system with battery storage under various load and auxiliary energy conditions". Applied Energy 2009;86(9):138794.DOI: 10.1016/j.apenergy.2008.12.015

[13] Diaf, S., Belhamelb, M., Haddadic, M., and Louchea, A., "Technical and Economic Assessment of Hybrid Photovoltaic/Wind System with Battery Storage in Corsica Island," Energy Policy, Vol. 36, No.2, pp. 743-754, (2008).

[14] A. Chauhan, R.P. Saini, "A review on Integrated Renewable Energy System based power generation for stand-alone applications: Configurations, storage options, sizing methodologies and control", Renewable and Sustainable Energy Reviews, vol. 38 pp. 99-120, (2014). DOI:10.1016/j.rser.2014.05.079

[15] A. Maleki, A. Askarzadeh, "Comparative study of artificial intelligence techniques for sizing of a hydrogen-based stand-alone photovoltaic/wind hybrid system", International Journal of Hydrogen Energy, Vol.39, Issue 19 (2014), pp. 9973-9984. DOI: 10.1016/j.ijhydene.2014.04.147

[16] I. Patrao, E. Figueres, G. Garcerá, R. González-Medina, "Microgrid architectures for low voltage distributed generation", Renewable and Sustainable Energy Reviews, Vol.43, March 2015, pp. 415-424. DOI: 10.1016/j.rser.2014.11.054

[17] J.J. Justo, F. Mwasilu, J. Lee, J.W. Jung, “AC-microgrids versus DCmicrogrids with distributed energy resources: A review", Renewable and Sustainable Energy Reviews, 24 (2013) 387-405,. DOI: 10.1016/j.rser.2013.03.067

[18] Nelson, D.B., Nehrir, M.H., Wang, C. "Unit sizing and cost analysis of stand-alone hybrid wind/PV/fuel cell power generation systems", Renewable Energy, Vol.31, Issue 10, August 2006, pp.1641-1656. DOI: 10.1016/j.renene.2005.08.031

[19] B. Bhandari, S.R. Poudel, K-T. Lee, S-H. Ahn, "Mathematical Modeling of Hybrid Renewable Energy System: A Review on Small Hydro-SolarWind Power Generation", International Journal of Precision Engineering and Manufacturing-Green Technology, Vol. 1, No. 2, pp. 157-173. DOI:10.1007/s40684-014-0021-4
[20] A. Raihani, A. Hamdoun, O. Bouattane, B. Cherradi, A. Mesbahi, "An Optimal Management System of a Wind Energy Supplier", Smart Grid and Renewable Energy, 2011, 2, 349-358 DOI:10.4236/sgre.2011.24040

[21] A. Raihani, A. Hamdoun, O. Bouattane, B. Cherradi, A. Mesbahi, "Toward an accurate assessment of wind energy platform of Mohammedia city, Morocco", IRACST - Engineering Science and Technology: An International Journal (ESTIJ), Vol.2, No. 5, October 2012.

[22] A. Ortiz-Conde, D. Lugo-Munoz, "An Explicit Multiexponential Model as an Alternative to Traditional Solar Cell Models With Series and Shunt Resistances", IEEE Journal of Photovoltaics, Vol. 2, No. 3, JULY 2012, pp. 261-268. DOI: 10.1109/JPHOTOV.2012.2190265

[23] P. Bajpai, V. Dash, "Hybrid renewable energy systems for power generation in stand-alone applications: A review", Renewable and Sustainable Energy Reviews $16 \quad$ (2012) 2926- 2939. DOI:10.1016/j.rser.2012.02.009

[24] E. Dursun, O. Kilic, "Comparative evaluation of different power management strategies of a stand-alone PV/Wind/PEMFC hybrid power system", International Journal of Electrical Power \& Energy Systems, Vol. 34, Issue 1, January 2012, pp. 81-89, DOI: 10.1016/j.ijepes.2011.08.025

[25] S. Bogdan, Z.B. Salameh, "Methodology for optimally sizing the combination of a battery bank and PV array in a wind/PV hybrid system". IEEE Transactions on Energy Conversion 11 (2), 367- 375. 1996

[26] J. F. Manwell et J. G. McGowan, "Lead Acid Battery Storage Model for Hybrid Energy Systems”, Solar Energy, vol. 50, n5, pp. 399-405, 1993.

[27] R. A. Jackey, "A Simple, Effective Lead-Acid Battery Modeling Process for Electrical System Component Selection", SAE SP, $\mathrm{n}^{\circ}$ 2130, pp. 1726, 2007.

[28] Cherif A., M Jraidi, A Dhouib, "A battery ageing model used in standalone PV systems", Journal of Power Sources, vol. 112, n 1, pp. 49-53, 2002.

[29] A.H. Anbuky, P.E. Pascoe, "VRLA battery state-of-charge estimation in telecommunication power systems", IEEE Trans. Ind. Electron., vol. 47, no.3, pp. 565-573, jun. 2000

[30] K. Kutluay, Y. Cadirci, Y.S. Ozkazanc, I. Cadirci, “ A new online stateof-charge estimation and monitoring system for sealed lead-acid batteries in telecommunication power supplies", IEEE Trans. Ind. Electron., vol. 52, no.5, pp. 1315-1327, Oct. 2005

[31] A.Rebbani, O.Bouattane, L.Bahatti, M.Zazoui, "An Efficient Electric Charge Transfer Device for Intelligent Storage Units". Open Journal of Energy Efficiency, 3, 50-63, (2014). DOI: 10.4236/ojee.2014.33006

[32] O.C. Onar, M. Uzunoglu, M.S. Alam, "Dynamic modeling, design and simulation of a wind/fuel cell/ultra-capacitor-based hybrid power generation system", Journal of Power Sources, Vol. 161, Issue 1, (2006), pp. 707-722. DOI:10.1016/j.jpowsour.2006.03.055

[33] M. Uzunoglu, O.C. Onar, M.S. Alam, "Modelling, control and simulation of a $\mathrm{PV} / \mathrm{FC} / \mathrm{UC}$ based hybrid power generation system for stand-alone applications", Renewable Energy, Vol. 34, Issue 3, (2009), pp. 509-520. DOI:10.1016/j.renene.2008.06.009

[34] J. Lia, R. Xionga, Hao Mua, B. Cornélusseb, P. Vanderbemdenb, D. Ernstb, W. Yuanc, "Design and real-time test of a hybrid energy storage system in the microgrid with the benefit of improving the battery lifetime", Applied Energy, Vol. 218, pp.470-478, May 2018. DOI: 10.1016/j.apenergy.2018.01.096

[35] S.F. Tie, C.W. Tan, A review of energy sources and energy management system in electric vehicles, Renew. Sustain. Energy Rev. 20 (2013) 82102, DOI: 10.1016/j.rser.2012.11.077. 